\title{
A note on ' $N$-fixed point theorems for nonlinear contractions in partially ordered metric spaces'
}

\author{
Erdal Karapınar ${ }^{*}$, Antonio Roldán, Concepción Roldán and Juan Martínez-Moreno
}

\section{"Correspondence:}

ekarapinar@atilim.edu.tr; erdalkarapinar@yahoo.com Department of Mathematics, Atilim University, İncek, Ankara 06836, Turkey

\begin{abstract}
In this note we prove that a kind of mappings depending on $k$ arguments introduced in (Paknazar et al. in Fixed Point Theory Appl. 2013:111, 2013) only depend on their first argument. Therefore, results in that paper reduce to the unidimensional case. We also include some commentaries about the different notions of multidimensional fixed point.

MSC: 46T99; 47H10;47H09; 54H25

Keywords: partially ordered set; fixed point; contractive mapping; mixed monotone property
\end{abstract}

Recently, Paknazar et al. [1] introduced the concept of new $g$-monotone property for a mapping $F: X^{k} \rightarrow X$ as follows.

Definition 1 (Paknazar et al. [1], Definition 2.2) Let $X$ be a non-empty set (provided with a partial order $\preccurlyeq)$, and let $g: X \rightarrow X$ and $F: X^{k} \rightarrow X(k \geq 2)$ be two given mappings. $F$ is said to have the new g-monotone property if $F$ is monotone $g$-non-decreasing in its first argument. That is, for any $\left(x_{1}, x_{2}, \ldots, x_{k}\right),\left(y_{1}, y_{2}, \ldots, y_{k}\right) \in X^{k}$,

$$
g\left(x_{1}\right) \preccurlyeq g\left(y_{1}\right) \quad \Rightarrow \quad F\left(x_{1}, x_{2}, \ldots, x_{k}\right) \preccurlyeq F\left(y_{1}, y_{2}, \ldots, y_{k}\right) .
$$

We prove that there is not a wide range of mappings verifying this condition.

Theorem 2 Let $(X, \preccurlyeq)$ be a partially ordered set, and let $g: X \rightarrow X$ and $F: X^{k} \rightarrow X(k \geq 2)$ be two given mappings such that $F$ has the new g-monotone property. Then there exists a unique g-non-decreasing mapping $f: X \rightarrow X$ such that

$$
F\left(x_{1}, x_{2}, \ldots, x_{k}\right)=f\left(x_{1}\right) \quad \text { for all }\left(x_{1}, x_{2}, \ldots, x_{k}\right) \in X^{k}
$$

Therefore, $F$ only depends on its first variable and all results in [1] can be reduced to the unidimensional case.

Proof Fix a point $\left(z_{2}, z_{3}, \ldots, z_{k}\right) \in X^{k-1}$ and define $f: X \rightarrow X$ by $f(x)=F\left(x, z_{2}, z_{3}, \ldots, z_{k}\right)$ for all $x \in X$. To prove (1), let $\left(x_{1}, x_{2}, \ldots, x_{k}\right) \in X^{k}$ be arbitrary. Since $g\left(x_{1}\right) \preccurlyeq g\left(x_{1}\right)$, the new

\section{Springer}

@2013 Karapınar et al.; licensee Springer. This is an Open Access article distributed under the terms of the Creative Commons Attribution License (http://creativecommons.org/licenses/by/2.0), which permits unrestricted use, distribution, and reproduction in any medium, provided the original work is properly cited. 
$g$-monotone property yields

$$
\begin{aligned}
& F\left(x_{1}, x_{2}, x_{3}, \ldots, x_{k}\right) \preccurlyeq F\left(x_{1}, z_{2}, z_{3}, \ldots, z_{k}\right) \text { and } \\
& F\left(x_{1}, z_{2}, z_{3}, \ldots, z_{k}\right) \preccurlyeq F\left(x_{1}, x_{2}, x_{3}, \ldots, x_{k}\right),
\end{aligned}
$$

which means that $F\left(x_{1}, x_{2}, x_{3}, \ldots, x_{k}\right)=F\left(x_{1}, z_{2}, z_{3}, \ldots, z_{k}\right)=f\left(x_{1}\right)$.

Furthermore, suppose that $x, y \in X$ are such that $g(x) \preccurlyeq g(y)$. By the new $g$-monotone property, we observe that

$$
f(x)=F\left(x, z_{2}, z_{3}, \ldots, z_{k}\right) \preccurlyeq F\left(y, z_{2}, z_{3}, \ldots, z_{k}\right)=f(y),
$$

that is, $f$ is a $g$-non-decreasing mapping. The unicity of $f$ is obvious.

The main result in Paknazar et al. [1] is the following theorem.

Theorem 3 (Paknazar et al. [1], Theorem 2.5$)$ Let $(X, \preccurlyeq, d)$ be a partially ordered complete metric space, and let $F: X^{k} \rightarrow X$ and $g: X \rightarrow X$ be two given mappings such that $F$ has a new $g$-monotone property, $g$ is continuous, $F\left(X^{k}\right) \subset g(X)$ and $g$ commutes with $F$. Assume that there exists a continuous function $\varphi:[0,+\infty) \rightarrow[0,+\infty)$, satisfying

(i) $\varphi(t)<t$ for $t>0$ and $\varphi(0)=0$,

(ii) $\lim _{r \rightarrow t^{+}} \varphi(r)<t$ for each $t>0$,

such that

$$
d\left(F\left(x_{1}, \ldots, x_{k}\right), F\left(y_{1}, \ldots, y_{k}\right)\right) \leq \varphi\left(\frac{d\left(g x_{1}, g y_{1}\right)+\cdots+d\left(g x_{k}, g y_{k}\right)}{k}\right)
$$

for all $x_{j}, y_{j}(j \in\{1,2, \ldots\})$ so that $g\left(x_{2 i-1}\right) \preccurlyeq g\left(y_{2 i-1}\right)$ for all $i \in\left\{1,2, \ldots,\left[\frac{k+1}{2}\right]\right\}$ and $g\left(y_{2 i}\right) \preccurlyeq$ $g\left(x_{2 i}\right)$ for all $i \in\left\{1,2, \ldots,\left[\frac{k}{2}\right]\right\}$, and suppose that there exist $x_{1}^{0}, x_{2}^{0}, \ldots, x_{k}^{0} \in X$ such that

$$
\begin{aligned}
& g\left(x_{2 i-1}^{0}\right) \preccurlyeq F\left(x_{2 i-1}^{0}, x_{2 i}^{0}, \ldots, x_{k}^{0}, x_{1}^{0}, \ldots, x_{2 i-2}^{0}\right) \quad \text { for all } i \in\left\{1,2, \ldots,\left[\frac{k+1}{2}\right]\right\}, \\
& g\left(x_{2 i}^{0}\right) \succcurlyeq F\left(x_{2 i}^{0}, x_{2 i+1}^{0}, \ldots, x_{k}^{0}, x_{1}^{0}, x_{2}^{0} \ldots, x_{2 i-1}^{0}\right) \quad \text { for all } i \in\left\{1,2, \ldots,\left[\frac{k}{2}\right]\right\} .
\end{aligned}
$$

Also suppose that either

(a) $F$ is continuous, or

(b) $X$ has the following property:

(i) If a non-decreasing sequence $\left\{x_{n}\right\} \rightarrow x$, then $x_{n} \preccurlyeq x$ for all $n$;

(ii) If a non-increasing sequence $\left\{y_{n}\right\} \rightarrow y$, then $y_{n} \succcurlyeq y$ for all $n$.

Then there exist $x_{1}, x_{2}, \ldots, x_{k} \in X$ such that

$$
g\left(x_{i}\right)=F\left(x_{i}, x_{i+1}, \ldots, x_{k}, x_{1}, x_{2}, \ldots, x_{i-1}\right) \quad \text { for all } i \in\{1,2, \ldots k\} .
$$

That is, $F$ and $g$ have a $k$-coincidence point.

Firstly, notice that if $\varphi$ is continuous and $\varphi(t)<t$ for all $t>0$, then $\varphi(0)=0$, so the condition $\varphi(0)=0$ in (i) can be avoided. But mainly, we claim that this theorem is an immediate consequence of the following unidimensional result (a two-dimensional version of the fol- 
lowing result can be found in [2], a multidimensional version is in [3]), which can be seen as a natural extension of Ran and Reurings' theorem [4] and Nieto and Rodríguez-López's theorem [5].

Theorem 4 Let $(X, d, \preccurlyeq)$ be a complete partially ordered metric space, and let $T, g: X \rightarrow X$ be two mappings such that $T$ is g-non-decreasing and $g$ is continuous. Suppose that there exists $\varphi:[0,+\infty) \rightarrow[0,+\infty)$ such that $\varphi(t)<t$ and $\lim _{r \rightarrow t^{+}} \varphi(r)<t$ for each $t>0$, verifying

$$
d(T(x), T(y)) \leq \varphi(d(g(x), g(y))) \quad \text { for all } x, y \in X \text { such that } g(x) \succcurlyeq g(y) .
$$

Also assume that $T$ is continuous or $(X, d, \preccurlyeq)$ is regular (that is, it verifies condition (b) of the previous theorem). If there exists a point $x_{0} \in X$ such that $g\left(x_{0}\right) \preccurlyeq T\left(x_{0}\right)$, then $T$ and $g$ have a coincidence point, that is, a point $x \in X$ such that $g(x)=f(x)$.

To prove our claim, notice that if $F$ verifies the new $g$-monotone property, we have showed that there exists a mapping $f: X \rightarrow X$ such that

$$
F\left(x_{1}, x_{2}, \ldots, x_{k}\right)=f\left(x_{1}\right) \quad \text { for all }\left(x_{1}, x_{2}, \ldots, x_{k}\right) \in X^{k}
$$

When $f$ is continuous, then $f$ is continuous; since $F$ and $g$ commute, then $f$ and $g$ commute; since $F\left(X^{k}\right) \subset g(X)$, then $f(X) \subset g(X) ; g\left(x_{1}^{0}\right) \preccurlyeq F\left(x_{1}^{0}, x_{2}^{0}, \ldots, x_{k}^{0}\right)=f\left(x_{1}^{0}\right)$ and similarly $g\left(x_{2}^{0}\right) \succcurlyeq$ $f\left(x_{1}^{0}\right)$; furthermore, the contractivity condition is similarly proved. Classical techniques assure that $f$ and $g$ have a coincidence point, that is, there is $x \in X$ such that $g(x)=f(x)$. Therefore $(x, x, \ldots, x) \in X^{k}$ is a $k$-coincidence point between $F$ and $g$, that is, $g(x)=f(x)=$ $F(x, x, \ldots, x)$.

To end this note, we include some considerations about the notion of multidimensional fixed point that researchers could take into account. Let $F: X^{k} \rightarrow X$ be a mapping. After the appearance of Guo and Lakshmikantham's notion of coupled fixed point (see [6]),

$$
x=F(x, y) \text { and } y=F(y, x) \text {, }
$$

Berinde's notion of tripled fixed point (see [7]),

$$
x=F(x, y, z), \quad y=F(y, x, y) \quad \text { and } \quad z=F(z, y, x),
$$

and Karapınar and Luong's notion of quadrupled fixed point (see $[8,9])$,

$$
x=F(x, y, z, t), \quad y=F(y, z, t, x), \quad z=F(z, t, x, y) \quad \text { and } \quad t=F(t, x, y, z) \text {, }
$$

some authors have paid attention to the multidimensional case. A first attempt to generalize this notion was given by Berzig and Samet in [10]. We have to distinguish between two kinds of definitions.

- In some cases, one or more arguments do not have to appear in all equations. For instance, the following notion was given in [11] (and was also mentioned in Paknazar et al., Definition 1.12, although it was not used in that paper):

$$
x_{i}=F\left(x_{i}, x_{i-1}, \ldots, x_{2}, x_{1}, x_{2}, \ldots, x_{k-i+1}\right) \quad \text { for all } i \in\{1,2, \ldots, k\} .
$$


This definition can be interpreted as an extension of the second equation of Berinde and Borcut's notion, that is, $y=F(y, x, y)$. This case yields the equations systems in which some arguments do not appear. Besides Berinde and Borcut's second equation in the tripled case, if $k=4$, the corresponding system is

$$
\left\{\begin{array}{l}
x=F(x, y, z, t), \\
y=F(y, x, y, z) \quad(\text { no data for } t), \\
z=F(z, y, x, y) \quad(\text { no data for } t), \\
t=F(t, z, y, x) .
\end{array}\right.
$$

This could be a difficulty in proving some results and, furthermore, this case is not possible when a researcher is interested in a system whose equations involve, at the same time, all variables.

- In other cases, the arguments are permuted. For instance, the notion of $k$-fixed point introduced in Paknazar et al. (Definition 2.1) is as follows:

$$
x_{i}=F\left(x_{i}, x_{i-1}, \ldots, x_{n-1}, x_{n}, x_{1}, x_{2}, \ldots, x_{i-1}\right) \quad \text { for all } i \in\{1,2, \ldots, k\}
$$

(for simplicity, we do not consider the coincidence case involving a mapping $g$ ). This notion generalizes Karapınar and Luong's quadrupled concept, that is,

$$
\left\{\begin{array}{l}
x=F(x, y, z, t) \\
y=F(y, z, t, x) \\
z=F(z, t, x, y) \\
t=F(t, x, y, z)
\end{array}\right.
$$

However, we remark that the equation system (2) is not suitable to work with the classical mixed monotone property when $k$ is odd. For instance, if $k=5$ and $F$ is monotone non-decreasing in its odd arguments and monotone non-increasing in its even arguments, then the equations

$$
x_{1}=F\left(x_{1}, x_{2}, x_{3}, x_{4}, x_{5}\right) \quad\left(x_{1} \text { and } x_{5} \text { are placed in non-decreasing arguments of } F\right)
$$

and

$$
\begin{array}{r}
x_{2}=F\left(x_{2}, x_{3}, x_{4}, x_{5}, x_{1}\right) \quad\left(x_{1} \text { and } x_{5}\right. \text { are placed in arguments } \\
\text { of different monotone type of } F)
\end{array}
$$

do not let us to show the existence of fixed points using the classical mixed monotone property. Berinde and Borcut realized that this definition is not convenient, so they had to consider the equation $y=F(y, x, y)$. System (2) only works when $k$ is even. Obviously, Paknazar et al. succeeded in proving their main results in [1] because, as we have showed before, the new $g$-mixed monotone property is very restrictive.

Finally, we comment that a more convenient notion of $k$-fixed point was given by Roldán et al. in [12]. This definition has three advantages: (1) it describes how the arguments can be reordered or permuted, (2) it works with the classical mixed monotone property, and 
(3) it extends Guo and Lakshmikantham's coupled case, Berinde's tripled case, Karapınar and Luong's quadrupled case and Berzig and Samet's multidimensional case. As we can easily see, the main result in [11] (that the reader can find in [1, Theorem 1.13] as a literature) is weaker than the main result of Roldán et al. [12]. For more publications in this direction, see, e.g., [10, 13-17]. We also notice that Roldán et al. [18] proved that some multidimensional fixed point results can be reduced to the unidimensional case.

\section{Competing interests}

The authors declare that there is no conflict of interests regarding the publication of this article.

\section{Authors' contributions}

All authors contributed equally and significantly in writing this article. All authors read and approved the final manuscript.

\section{Acknowledgements}

The first author was supported by the Research Center, College of Science, King Saud University. The last three authors were supported by Junta the Andalucía through Projects FQM-268, FQM-235 and FQM-178 of the Andalusian CICYE.

Received: 23 August 2013 Accepted: 29 October 2013 Published: 22 Nov 2013

\section{References}

1. Paknazar, M, Eshaghi Gordji, M, de la Sen, M, Vaezpour, SM: N-Fixed point theorems for nonlinear contractions in partially ordered metric spaces. Fixed Point Theory Appl. 2013, 111 (2013)

2. Choudhury, BS, Kundu, A: A coupled coincidence point result in partially ordered metric spaces for compatible mappings. Nonlinear Anal. 73, 2524-2531 (2010)

3. Wang, S: Coincidence point theorems for G-isotone mappings in partially ordered metric spaces. Fixed Point Theory Appl. 2013, 96 (2013)

4. Ran, ACM, Reurings, MCB: A fixed point theorem in partially ordered sets and some applications to matrix equations. Proc. Am. Math. Soc. 132, 1435-1443 (2004)

5. Nieto, JJ, Rodríguez-López, R: Contractive mapping theorem in partially ordered sets and applications to ordinary differential equations. Order 22, 223-239 (2005)

6. Guo, D, Lakshmikantham, V: Coupled fixed points of nonlinear operators with applications. Nonlinear Anal. 11, 623-632 (1987)

7. Berinde, V, Borcut, M: Tripled fixed point theorems for contractive type mappings in partially ordered metric spaces. Nonlinear Anal. 74, 4889-4897 (2011)

8. Karapınar, E: Quadruple fixed point theorems for weak $\phi$-contractions. ISRN Math. Anal. 2011, Article ID 989423 (2011)

9. Karapınar, E, Luong, NV: Quadruple fixed point theorems for nonlinear contractions. Comput. Math. Appl. 64, 1839-1848 (2012)

10. Berzig, M, Samet, M: An extension of coupled fixed point's concept in higher dimension and applications. Comput. Math. Appl. 63, 1319-1334 (2012)

11. Eshaghi Gordji, M, Ramezani, M: N-Fixed point theorems in partially ordered metric spaces. Preprint

12. Roldán, A, Martínez-Moreno, J, Roldán, C: Multidimensional fixed point theorems in partially ordered complete metric spaces. J. Math. Anal. Appl. 396(2), 536-545 (2012)

13. Roldán, A, Martínez-Moreno, J, Roldán, C, Karapınar, E: Multidimensional fixed point theorems in partially ordered complete partial metric spaces under $(\psi, \varphi)$-contractivity conditions. Abstr. Appl. Anal. 2013, Article ID 634371 (2013)

14. Karapınar, E, Roldán, A, Martínez-Moreno, J, Roldán, C: Meir-Keeler type multidimensional fixed point theorems in partially ordered metric spaces. Abstr. Appl. Anal. 2013, Article ID 406026 (2013)

15. Aydi, H, Karapınar, E, Mustafa, Z: Some tripled coincidence point theorems for almost generalized contractions in ordered metric spaces. Tamkang J. Math. 44(3), 233-251 (2013)

16. Karapınar, E, Shatanawi, W, Mustafa, Z: Quadruple fixed point theorems under nonlinear contractive conditions in partially ordered metric spaces. J. Appl. Math. 2012, Article ID 951912 (2012)

17. Mustafa, Z, Aydi, $H$, Karapınar, E: Mixed $g$-monotone property and quadruple fixed point theorems in partially ordered metric spaces. Fixed Point Theory Appl. 2012, 71 (2012)

18. Roldán, A, Martínez-Moreno, J, Roldán, C, Karapınar, E: Some remarks on multidimensional fixed point theorems. Fixed Point Theory (in press)

10.1186/1687-1812-2013-310

Cite this article as: Karapınar et al.: A note on ' $\mathrm{N}$-fixed point theorems for nonlinear contractions in partially ordered metric spaces'. Fixed Point Theory and Applications 2013, 2013:310 